\title{
Construction and Practice of Innovative Management Talents Training Mode in Enterprise Transformation and Upgrading
}

\author{
Huimin Chen \\ College of Teacher Education, Qujing Normal University, Qujing Yunnan, 655011, China
}

Keywords: Enterprise transformation and upgrading, Management talent, Cultivation mode.

\begin{abstract}
Enterprise transformation and upgrading enjoys a good interaction with the transformation of management major in newly-built local undergraduate universities. Institutions of higher education, especially those newly-established local universities, must act in accordance with enterprises' new requirements for the quality of management personnel to realize transformation and upgrading, build a cultivation mode for innovative management talents that meet those requirements, and cultivate some innovative management talents needed by the transformation and upgrading work of enterprises, thus speeding up the transformation and upgrading process, realizing the enrichment and development of the theory regarding enterprise transformation and upgrading.
\end{abstract}

\section{Positive interaction mechanism between the regional industrial transformation and upgrading and the transformation and development of newly-built local undergraduate colleges}

"The so-called industrial upgrading refers to the transformation process from traditional industries which mainly rely on the labor force and input of natural resources to modern industries that mainly depend on technology and management innovation." [1] The general change law of enterprise transformation and upgrading is led by "innovation-driven" technology [2] and innovative management talent. Transformation and upgrading of enterprises and the transformation and development of newly-built local undergraduate colleges and universities are mutually promoted, as shown in Figure 1. On the one hand, enterprise urgently needs innovative management personnel to lead and promote the transformation and upgrading process; on the other hand, the transformation and upgrading of enterprises provide numerous job opportunities for innovative management personnel, further enhance the transformation and development of higher education, especially that of new local colleges, achieve full employment of college graduates and comprehensively improve the quality of college students' employment, thus realizing the positive interaction between the transformation and upgrading of enterprises and that of local newly-built undergraduate colleges, as shown in Figure 1. 


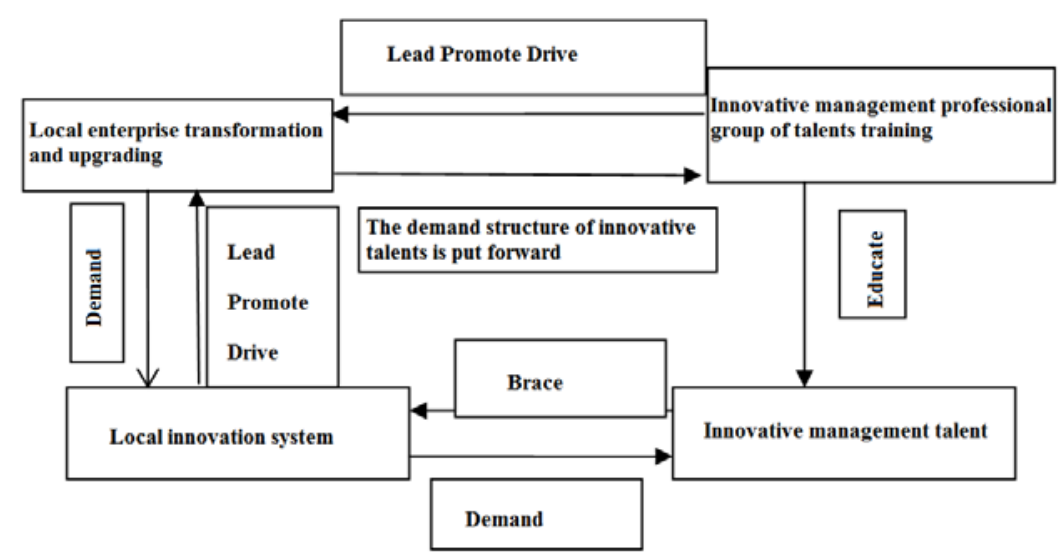

Fig. 1. Interaction diagram of enterprise transformation and upgrading and the talent training mode for management specialty group

According to our investigation on the quality structure of management personnel required by the transformation and upgrading of local enterprises, university students whose major are management are mainly engaged in management work in enterprises that are undergoing transformation and upgrading, and those students must be able to skillfully conduct innovative enterprise management, guide enterprises to complete the transformation and upgrading work, and bear lofty professional ethics, open international vision, solid theoretical knowledge, good business management skills, as well as rich experience in enterprise management. The trained college students must have high professional ethics, excellent innovation ability, high level of entrepreneurship and unique personality characteristics. Specifically include:

\section{Noble professional ethics}

Noble professional ethics is not only the most basic requirement to enterprise management personnel for enterprise transformation and upgrading, but also an important factor to be considered by those enterprises under transformation and upgrading in their recruitment of enterprise management personnel, thus making colleges and universities attach great importance to the cultivation of students' lofty professional ethics [3].

\section{Excellent innovation management skills}

\section{Strong learning ability}

Management-related major is of strong timeliness, especially during enterprises' transformation and upgrading, because the management subject, management object, management method and management skills are all constantly developing and changing, which is seen as a dynamic development process, and there are even often some unexpected events. Therefore, the transformation and development of management major must focus on improving students' learning ability.

\section{Strong innovation ability}

Enterprise transformation and upgrading is driven by technology and management innovation, while management innovation is driven, led, promoted and propelled by the innovation of management personnel. [4]

\section{High level of entrepreneurship}

Entrepreneurship refers to entrepreneurs' hope to increase corporate profits to highlight their management capabilities through their own innovation, thus obtaining the superiority embodied in the recognition and respect of enterprises and society. In the process of enterprise transformation and upgrading, the power of enterprise transformation and upgrading is mainly derived from the profit-driven force of enterprise innovation and entrepreneurship.

Personality characteristics of management talents 
Students' personality is the premise and foundation of innovation. These students who do not have their own personality characteristics and have no independent opinions in enterprise management can never be creative talents.

In short, better transformed and upgraded regions and enterprises always attach great importance to the introduction and cultivation of innovative entrepreneurial talent, for example, Guangdong province has proactively followed the principle of "introduce a number of high-level innovation and entrepreneurial talent, accelerate the industrial transformation and upgrading” [5], thereby having promoted the industrial transformation and upgrading of Guangdong province.

\section{System construction of innovative enterprise management personnel training mode in enterprise transformation and upgrading}

In accordance with the requirements of enterprise transformation and upgrading for management talents' innovation ability structure, combined with the characteristics of management specialty construction in universities, an innovative management personnel training mode to support local enterprises transformation and upgrading has been established, which mainly includes:

a). The overall framework of the innovation-oriented management personnel training mode to support the transformation and upgrading of local enterprises

The overall framework of the innovation-oriented management personnel training mode to support the transformation and upgrading of local enterprises can be summarized as "the five one", namely, "determine a training concept", "build an innovative management talent training model”, "create an innovative cultivation system", "launch an innovative training platform" and " form a good interaction mechanism”。

b. The basic content of management personnel training mode for enterprise transformation and upgrading

The principle of innovative management talents training to support transformation and upgrading of local enterprises was established

According to the survey on the demand of local enterprises transformation and upgrading for enterprise management personnel, the training idea of management specialty group in local undergraduate colleges is to cultivate innovative management talents. The concept of innovative management talent better embodies the talent cultivation idea of "mutual adaptability, individual adaptability and the inner adaptability", among which the mutual adaptability is mainly reflected in the supply adaptability between the transformation and upgrading of local enterprises and talent cultivation of management specialty group.

\section{Quality structure of innovative management talents was build}

\section{Quality structure of innovative management talents}

Given the five qualities and abilities that innovative management personnel should have for enterprise transformation and upgrading, including lofty professional ethics, strong learning ability, strong innovation ability, high level of entrepreneurship and distinct personality, we have built professional quality training mode, learning ability and innovation training mode, entrepreneurship cultivation mode, and the training mode of highlighting personality characteristics, so as to get innovative management personnel trained to support enterprise transformation and upgrading. A platform for innovative management personnel training to support enterprise transformation and upgrading was built

A multi-dimensional platform to cultivate college students was established: to cultivate and improve students' professional ethics mainly through classroom teaching; in the reform of curriculum teaching, problem-based and research-based teaching method was adopted to enhance students' learning ability and innovation ability; in business administration, marketing and other laboratories, emergent problems in management were created to develop students' ability to solve problems creatively and 
strengthen student's experimental experience; in the industry-university-research base, students' innovation ability was trained by solving the practical problems occurred in management; theoretical teaching and practical teaching were used to cultivate students' entrepreneurship; to cultivate and improve students' ability of innovation and entrepreneurship through extracurricular activities and entrepreneurial practice; to encourage students to participate in scientific research and foster students' innovation and entrepreneurship awareness in the process.

An innovative management personnel training module was built to support enterprise transformation and upgrading

Under the guidance of the innovation-oriented management personnel training concept in support of enterprise transformation and upgrading, based on the quality and ability structure of innovative management talent demanded by enterprise transformation and upgrading, we divided the training module into several modules including basic management knowledge module and innovation ability training module, practical and experimental innovation experience module, as well as student individual training module.

Innovative management personnel training approach to support enterprise transformation and upgrading was constructed

The specific method is: teaching promotion approach - adopted a five-in-one interactive teaching mode of "theory teaching - problem-based teaching - research-based teaching - scene simulation teaching - practical experience teaching"; the approach of training experience was mainly done through the launch of five-in-one experience method, namely innovative entrepreneurial experience experimental training experience - practice experience; the approach of education was mainly conducted through "hidden curriculum" such as innovative campus culture, platform construction for college students' science and technology innovation and entrepreneurship competition, creation of college students' pioneering park, and creation of innovative practice platform for college students, so as to educate, cultivate and improve the innovative spirit of college students, thus better supporting the transformation and upgrading of local enterprises.

\section{Innovative management personnel training system was established to support industrial transformation and upgrading}

We, according to the management personnel training mode of local colleges and universities in transition, has built an innovative management personnel training system, which is mainly composed of five systems:

a). An curriculum system for innovative management personnel training was built to support enterprise transformation and upgrading. The specific courses consist of eight modules including general knowledge, basic course of management science, basic courses of relevant majors, professional courses, international vision development, innovation and entrepreneurship course, experimental and training course, and elective professional course. The course construction of each module should focus on the target of cultivating innovative management talent to support enterprise transformation and upgrading so as to foster students' ability of innovation and entrepreneurship.

b). The practice teaching system of innovation and entrepreneurship was improved. Innovation and entrepreneurship practice is an important channel to improve students' innovation ability, according to the target of cultivating innovative management talent to support enterprise transformation and upgrading, we built curriculum practice innovation system, innovative professional ability training in management and innovative practice teaching system for practical training and graduation practice, each course formulated innovative practice outline and was strictly implemented; based on the cultivation of innovative management personnel for enterprise transformation and upgrading, we had vocational ability training course, for example, students majored in marketing management were asked to creatively design a product with local characteristics or a marketing plan to promote new products, etc. At the same time, a industry-university-research practice base was constructed, which allows students to conduct better innovative management on new problems emerged in the transformation and upgrading of enterprises, thus further cultivating students' innovative ability. 
c). We built a comprehensive laboratory of management science and a comprehensive online experimental system, formed a more perfect integrated practical training system, set new problems constantly emerged in management during experiment teaching, and guided students to solve these new problems creatively, thereby further cultivating and improving students' sense of innovation, innovative spirit and innovative ability.

d). To support enterprise transformation and upgrading, we took innovative management personnel training as the idea, created a systematic curriculum reform system, laid emphasis on students' ability to discover problems, analyze problems and creatively solve problems while teaching.

e). A contingent of teachers with high quality to cultivate innovative management talent was built. The institute established a team of teachers with strong theoretical knowledge, innovative research ability as well as rich management experience, thus providing qualified teachers to ensure the success of innovative management talents training.

\section{A resource platform was established.}

From an overall perspective of innovative management personnel training to support enterprise transformation and upgrading, we systematically established a teaching platform for management practice, achieved an innovative management practice teaching platform which made curriculum connected to each other, bear progressive increase in training level, and enjoy industry-university-research harmony, initially built a new network-based and three-dimensional practice teaching system of management specialty, thus forming a school-based open innovative teaching platform which was an integration of curriculum innovation, school innovation, integrated innovation, enterprise innovation and other innovative teaching systems.

\section{A running mechanism was formed.}

According to the target of innovative management personnel training for enterprise transformation and upgrading, we established a training system of innovative management talents, achieved the formation of innovative talent training ideas, objectives, specifications, platforms, modules, approaches and forms, etc, and put forward an innovative operating form of "classroom teaching innovation + training innovation + practice innovation + dual tutorial system + development and training of students' personality characteristics”, therefore, we would cultivate the new type of management personnel needed for the transformation and upgrading of enterprises, and also cultivate and develop students' personality characteristics, and form the important innovation in talent cultivation mechanism.

\section{Practice performance of innovative management personnel training mode in enterprise transformation and upgrading}

After the construction of innovative management personnel training mode for enterprise transformation, we carried out systematic practice and obtained good results, which were mainly manifested in:

\section{Students' innovative ability became stronger}

Through the practice of innovative management talent model for local enterprise transformation, students who majored in management enjoyed stronger professional theoretical knowledge, management ability, management skills and innovation ability.

\section{Students enjoyed high comprehensive quality}

Student's professional management quality and professional non-management quality were high and $80 \%$ of the students had access to vocational qualification certificates, among them, $98 \%$ of the students who majored in accounting obtained the qualification certificate of accounting while $70 \%$ of these students received assistant accountant qualification certificate, meanwhile, the pass rate of 
CET-4 and CET-6 of graduated college students were high, which showed their relatively high level in English, and all students passed the national computer test. Students' international vision was open and most of they received praise from their company.

\section{Better promoted the transformation and upgrading of local enterprises}

The practice of innovative management personnel training mode for enterprise transformation cultivated innovative management talents that would help local enterprise transformation and upgrading, and these innovative management personnel better met the needs of local enterprises to realize transformation and upgrading, better reflected the demand of "demand oriented, docking industry, business" [6], thus achieving a higher employment rate of college graduates. According to the investigation on university graduates, local enterprises in transformation and upgrading generally agreed with the high innovation quality of graduates majored in management of our school, agreed that these graduates had solid professional knowledge, strong management ability, sophisticated management skills, ability to creatively carry out work, and could guide and promote the transformation and upgrading of local enterprises, besides, these graduates were also well qualified for management. The employment rate of graduates majored in management was more than $98 \%$ for three consecutive years, and there was a gradual increase in the number of entrepreneurs, which better promoted the transformation and upgrading of local enterprises.

\section{Acknowledgments}

This paper is a project construction of key specialty conducted by newly-built undergraduate colleges in Yunnan province for transforming into university of applied sciences so as to support industrial upgrading: the phased achievements made by the management specialty construction of Qujing Normal University.

\section{References}

[1] Li Dong Hang. Reform of Higher Vocational Talents Training Mode in Industrial Upgrading, Vocational and Technical Education in China, 2013 (9) : 74.

[2] Yao Zhenghai, Yang Baohua, Ye Qing. Study on the cultivation of innovative talents based on the transformation and upgrading of the regional industry, Economic issue, 2013(10):87.

[3] Ding Shengqi. Go to Taiwan and view its education, Education paper collection, 2009 (9):10-12.

[4] Cheng Qingting. Entrepreneurs’ success, Leading science, 2015(5): 39 - 38

[5] Li Yumei. View talent as the first advantage and lead the industrial transformation and upgrading, China's talent, 2012(1): 26.

[6] Xu Qingyun. Reflection on the transformation of ordinary undergraduate colleges and universities, Journal of the National Institute of education administration, 2015 (3): 40. 